\title{
Optimization of conventional treatment of the surface water treatment plant of the city of Khenifra
}

\author{
Mariem Ennouhi ${ }^{1}$, Abdellah El Boukili ${ }^{2}$, Abderrahim El Hourch ${ }^{3}$, Aicha Guessous ${ }^{3}$, Abderrahim \\ Khadir ${ }^{4}$, Mohamed El Otmani ${ }^{4}$, Lahcen Hasnaoui ${ }^{4}$ and Mohammed El Azzouzi ${ }^{1, *}$ \\ ${ }^{1}$ Laboratoire de Spectroscopie, Modélisation Moléculaire, Matériaux et Environnement, Département de \\ Chimie, Faculté des Sciences, Université Mohammed V de Rabat, Morocco \\ ${ }^{2}$ Laboratory of Physical Chemistry of inorganic and organic Materials Normal Superior School, University \\ Mohammed V de Rabat, Morocco \\ ${ }^{3}$ Laboratoire de Matériaux, Nanomatériaux et Environnement, Faculté des Sciences, Université Mohammed V \\ de Rabat, Morocco \\ ${ }^{4}$ Office National de l'Electricité et de l'Eau Potable, Rabat, Morocco
}

\begin{abstract}
Treatment of the surface water of the city of Khenifra combines a conventional treatment and a membrane process unit (reverse osmosis). The conventional treatment in question uses an aluminium base reagent in the form of Aluminum sulphate that may cause leaks of Aluminum called "residual Aluminum" in the filtered water. The objective of this work is to study the elimination of residual aluminum, resulting from the conventional treatment, for a better operation of the demineralization unit by Reverse Osmosis, located downstream. Indeed, according to the requirements of the supplier of the membranes, the residual aluminum content should not exceed $0.05 \mathrm{mg} / \mathrm{L}$. The jar test remains the most used test, at the level of the laboratories, which allows optimizing the doses of treatment reagents to be used in a treatment plant; particularly the aluminum sulfate coagulant. Trials of the jar test were performed and had been optimized by the application of Doehlert experimental design.

The effectiveness of the treatment and the optimum conditions through the stages of treatment are achieved by monitoring the parameters: $\mathrm{pH}$, turbidity and residual aluminum.

The results of tests obtained by this method have shown that to achieve a better reduction of residual aluminum in filtered water $(0,03 \mathrm{mg} / \mathrm{L})$; it is necessary to reach a $\mathrm{pH}$ of 6.5 , using Sulfuric acid. The optimal dose of coagulant Aluminum sulfate determined under the conditions of the test is of the order of $18.5 \mathrm{mg} / \mathrm{L}$. On the other hand, the optimization of the treatment by the recirculation of sludge (in optimal doses) showed an improvement of the turbidity of filtered water, but without any effect on residual aluminum.
\end{abstract}

Keywords: Coagulation-Flocculation, Residual Aluminum, Jar-test, Reverse osmosis, Recirculation of sludge.

\section{Introduction}

Water is a natural resource that is necessary for the survival of humanity and the socio-economic development of nations ${ }^{1}$. To produce drinking water, raw water is first characterized, and then according to the quality parameters, water is treated in a treatment facility that must produce in all circumstances water quality that complies with the Moroccan standards related to drinking water. Raw water can have varying characteristics regarding suspended solid r, colloids, and organic matter concentrations and sometimes of high mineralization (chlorides, sulfates) ${ }^{2}$. To eliminate totally or partially these elements, the conception of the treatment facility may appeal to several processes ${ }^{3}$. Coagulation-flocculation is the most common treatment to eliminate the suspended solid and colloids present in water ${ }^{4-8}$.

The use of aluminum-based coagulant salt can lead to leaks of aluminum (residual aluminum) in treated water when the process is not well optimized. It is recalled according to the Moroccan water quality standards for drinking water (NM.03.7.001 (2006)) the maximum admissible value of Aluminum in drinking water is $0.20 \mathrm{mg} / \mathrm{L}$. Additionally, when the treatment system includes a membrane process (for the demineralization) ${ }^{9,10}$, it is necessary to meet the requirements of the manufacturer of the membrane, seeking an aluminum content less than $0.05 \mathrm{mg} / \mathrm{L}$ in the feed water of the membrane.

The Oum Errabia River is the main water resource for the Khenifra treatment plant. This surface 
water is characterized by strong variations of Total Suspended Solid (TSS) and high chlorides concentrations (due to the geological nature of the land crossed by these waters) ${ }^{11}$. The main coagulant used for the treatment of these waters is aluminum sulfate $^{12}$, and the produced water (by conventional treatment) is characterized by levels of residual aluminum that meet the requirements of the Moroccan water quality standard for drinking water. This value remains high for the membrane process. The objective of this study is to optimize the quality of the treated water upstream supply of reverse osmosis membranes, particularly the reduction of residual aluminum from the phase of clarification by the coagulant aluminum sulfate. The recirculation of sludge, which is part of the treatment process to improve the clarification has been studied to assess its effect on residual aluminum. Figure 1 presents a schematic overview of the various steps necessary to treat the water.

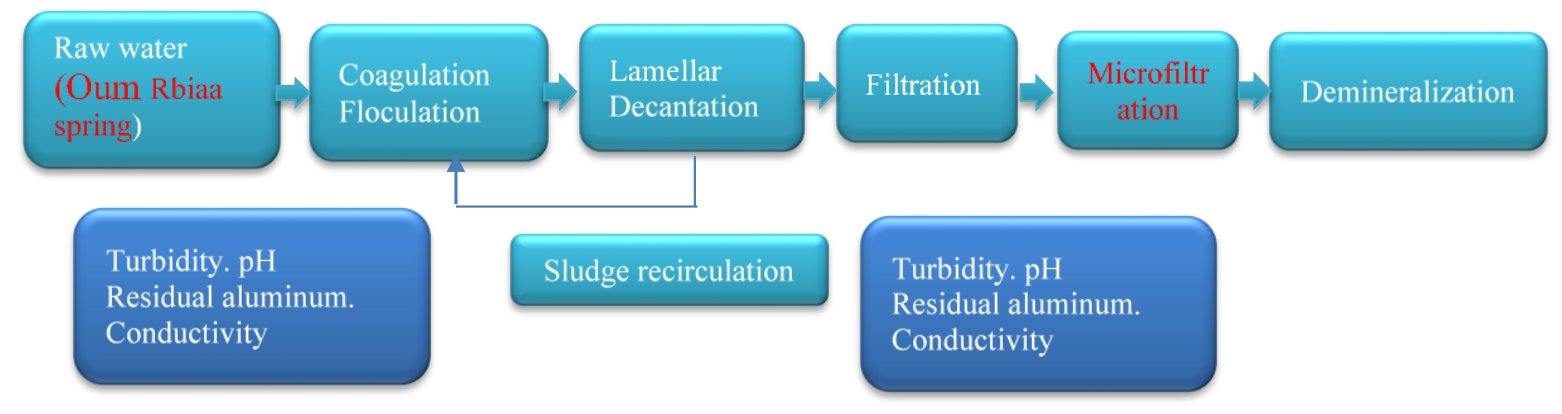

Figure 1. Simplified synopsis of the water treatment plant.

\section{Material and Methods}

\section{Flocculation test}

Flocculation at jar test performed in the laboratory has three phases: A fast agitation at a speed of $120 \mathrm{rpm}$ for 2 minutes, a slow agitation at a speed of $40 \mathrm{rpm}$ for 20 minutes and decantation for 30 minutes.

Flocculation tests conducted by acidification of the raw water using sulphuric acid (at a concentration of $10 \mathrm{~g} / \mathrm{L}$ ) to reduce the $\mathrm{pH}$ of the raw water until the optimal $\mathrm{pH}$, which corresponds to the minimum residual Aluminum using the experimental design method.

After settling, a certain amount of water is taken (all by avoiding a possible suspension of the floc thus formed). Then the parameters $\mathrm{pH}$, Turbidity and residual Aluminum are determined.

\footnotetext{
Preparation of the solution of Aluminum Sulphate

The solution of Aluminum Sulphate has been prepared by dissolving $10 \mathrm{~g}$ of Aluminum Sulphate $\left(\mathrm{Al}_{2}\left(\mathrm{SO}_{4}\right)_{3}\right)$ in one liter distilled water. Every $1 \mathrm{ml}$ of this solution corresponds to a treatment rate of 10 $\mathrm{mg} / \mathrm{L}$. The mud produced in the settling step of the treatment process has been used in the stage of flocculation. The concentration of suspended matter was determined by filtration of a volume of $5 \mathrm{ml}$ on a paper filter having a $5 \mu \mathrm{m}$ porosity.
}

\section{Experimental research methodology}

Several experiences are performed to find the optimal dose of aluminium sulphate. The method of the experimental plans was used to optimize them. This method determines and establishes the relationship between the factors and responses.

Response surface methodology is part of the method of design of experiments. This technique is intended to determine the variations of the function response to factors of significant influence in a quantitative way ${ }^{13,14}$.

Once the variables with a statistically significant influence on responses have been identified, Doehlert experimental model ${ }^{15}$ (Figure 2) is used to optimize the levels of these variables.

The number of required experience $(\mathrm{N})$ is given by $\mathrm{N}=\mathrm{n}^{2}+\mathrm{n}+\mathrm{n}_{0}$, where $\mathrm{n}$ is the number of variables and $\mathrm{n}_{0}$ is the number of central points. Answers to the central level of the variables are also performed to validate the model using experimental variance estimation. The experimental variables $\mathrm{Xi}$ were coded as $\mathrm{xi}$ according to the following equation 1 :

$\boldsymbol{x i}=\left(\left(\mathbf{X}_{\mathbf{i}}-\mathbf{X}_{\mathbf{0 i}}\right) / \Delta \mathbf{X}_{\mathbf{i}}\right.$

With $\boldsymbol{x i}$ is the coded value of the variable $\mathrm{I}^{\text {ème }}, \mathrm{X}_{\mathrm{i}}$ the natural value, $X_{\mathrm{oi}}$ the value at the centre point, $\Delta \mathrm{X}_{\mathrm{i}}$, the value of level change and $\omega_{\mathrm{i}}$ is the maximum value of the encoded variable. 


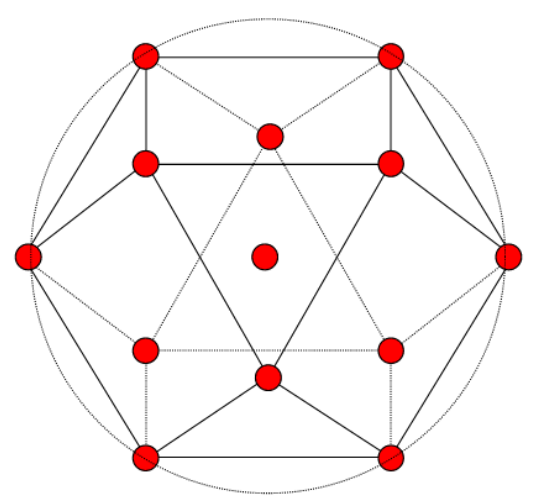

Figure 2. The Doehlert plan of three factors.

In our case, the study factors (i.e. factors whose levels are controlled in the design of experiments) are $\mathrm{pH}$, the dose of Aluminum sulphate and the rate of sludge recirculation. Initial and coded values corresponding (Table 1) are used for setting up experiments and model respectively. Exploitation of results is done by the linear regression method from the Nemrod.

Table1. The initial values and the corresponding coded values of the matrix of experience.

\begin{tabular}{|c|c|c|c|c|}
\hline & Factor XI & pH $(*)$ & $\begin{array}{r}\text { Dose of Aluminum Sulphates } \\
(\text { SA) mg/L (*) }\end{array}$ & $\begin{array}{c}\text { Rate of recirculation of } \\
\text { sludge g/L }\end{array}$ \\
\hline Low level & -1 & 6 & 11 & 0.3 \\
\hline High level & +1 & 7 & 26 & 0.6 \\
\hline
\end{tabular}

(*): The choice of the areas (see paragraph (III)).

\section{Results and discussion}

\section{The quality of the raw water}

The quality of the feed water of the Khenifra treatment plant is characterized by significant mineralization with high levels of chloride and high turbidity.

For the treatment of these waters, several jar-tests were carried out in the laboratory with the aim of determining the optimal dose of Aluminum sulphate and the optimal coagulation $\mathrm{pH}$ in order to reach low turbidity of filtered water and a low residual Aluminum content and thus meeting both the requirements of the Moroccan standard for drinking water quality and the requirements of the membrane manufacturer $(<0.05 \mathrm{mg} / \mathrm{L})$. Table 2 includes the results of a jar-test performed on a sample of raw water.

Table 2. Results of the jar-test test insert $\mathrm{pH}$ and turbidity of raw water.

\begin{tabular}{|c|c|c|c|c|c|c|c|c|c|}
\hline \multirow{4}{*}{ 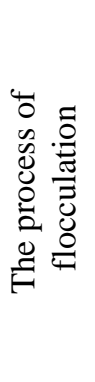 } & $\begin{array}{l}\text { Doses of coagulant } \\
\text { in } \mathrm{mg} / \mathrm{L}\end{array}$ & 10 & 15 & 20 & 30 & 40 & 50 & 60 & 70 \\
\hline & $\begin{array}{l}\text { Time to onset } \\
\text { of the flocs }\end{array}$ & $1 \mathrm{~min}$ & $1 \mathrm{~min}$ & $1 \min$ & $1 \mathrm{~min}$ & $1 \mathrm{~min}$ & $1 \min$ & $1 \mathrm{~min}$ & $1 \mathrm{~min}$ \\
\hline & Aspect of flocs & good & Good & good & good & good & good & good & good \\
\hline & $\begin{array}{c}\text { Rate of } \\
\text { Decantation }\end{array}$ & fast & Fast & fast & fast & fast & fast & fast & fast \\
\hline \multirow{3}{*}{ 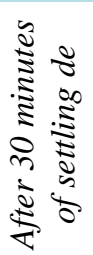 } & $\mathrm{pH}$ & 7.7 & 7.59 & 7.55 & 7.45 & 7.39 & 7.23 & 7.17 & 7.1 \\
\hline & Turbidity & 1.90 & 1.28 & 1.2 & 1.06 & 0.91 & 1 & 1.2 & 1.25 \\
\hline & Residual Aluminum & 0.35 & 0.32 & 0.28 & 0.2 & 0.18 & 0.13 & 0.14 & 0.11 \\
\hline
\end{tabular}

Raw water quality: $\mathrm{pH}=8.2$ Turbidity $=3$ NTU Residual Aluminum $=0 \mathrm{mg} / \mathrm{l}$ 
According to Table 2, the optimal dose of Aluminum sulphate to reach the lowest turbidity of water $(0.91 \mathrm{NTU})$ is of the order of $40 \mathrm{mg} / \mathrm{L}$. This dose corresponds to a $\mathrm{pH}$ of 7.39 with a residual Aluminum content of $0.18 \mathrm{mg} / \mathrm{L}$. Increasing the dose of Aluminum sulphate (up to $70 \mathrm{mg} / \mathrm{L}$ ) achieves turbidity of 1.25 NTU for the settled water and a residual Aluminum content of $0.11 \mathrm{mg} / \mathrm{L}$, and this is due to the decrease in $\mathrm{pH}$ to a value of about 7.1. This result confirmed that there is a relationship between $\mathrm{pH}$ and hydrolysis of aluminium ${ }^{16}$. These data show that the decrease in $\mathrm{pH}$ (by increasing the dose of Aluminum sulphate) resulted in a reduction of residual Aluminum. This content meets the requirements of the Moroccan water quality standards for drinking water (03.7.001 (V2006)) however; it is always greater than the recommendations of the membrane suppliers. To achieve an optimum of the residual Aluminum, a relation between the optimum
$\mathrm{pH}$ value of coagulation and the optimal dose of the Aluminum sulphate must be reached.

\section{Determination of the $\mathrm{pH}$ and the optimal dose of sulfate of alumina}

The experimental design method has been applied to optimize the parameters of the process. The experimental matrix proposed by Doehlert (1970) was used. The study was conducted first on two variables $(\mathrm{pH}=\mathrm{X} 1)$ and the dose of Aluminum sulphate $(\mathrm{SA}=\mathrm{X} 2)$. A model with two variables of Doehlert forms a regular hexagon where every corner and the centre represents an experiment.

From this study, it has been possible to express the optimization of residual Aluminum depending on the $\mathrm{pH}$ and the dose of Aluminum sulphate by the following equation 2 :

$$
Y=0.024+0.051 X_{1}+(-0.021) X_{2}+0.230 X_{1}^{2}+0.155 X_{2}^{2}(-0.138) X_{1} X_{2}
$$

The predicted residual Aluminum values (Y), using the equation 2, are given in Table 3 and compared with the experimental values found by the jar tests.

Table 3. Experimental design to two factors with the experimental values and the values predicted from residual Aluminum.

\begin{tabular}{|c|c|c|c|c|}
\hline $\begin{array}{l}\text { Number of } \\
\text { experience }\end{array}$ & $\begin{array}{c}\mathrm{X1} \\
(\mathrm{pH})\end{array}$ & $\begin{array}{c}\text { X2 } \\
\text { Sulphate Aluminium } \\
(\mathrm{mg} / \mathrm{L})\end{array}$ & $\begin{array}{l}\text { Value predicted } \\
\quad(\mathrm{y}) \mathrm{mg} / \mathrm{L}\end{array}$ & $\begin{array}{l}\text { Experimental value } \\
(y) \mathrm{mg} / \mathrm{L}\end{array}$ \\
\hline 1 & 7 & 18.5 & 0.21 & 0.25 \\
\hline 2 & 6 & 18.5 & 0.24 & 0.24 \\
\hline 3 & 6.8 & 25 & 0.20 & 0.21 \\
\hline 4 & 6.3 & 12 & 0.12 & 0.08 \\
\hline 5 & 6.8 & 12 & 0.33 & 0.39 \\
\hline 6 & 6.3 & 25 & 0.16 & 0.14 \\
\hline 7 & 6.5 & 18.5 & 0.03 & 0.04 \\
\hline 8 & 6.5 & 18.5 & 0.03 & 0.04 \\
\hline 9 & 6.5 & 18.5 & 0.03 & 0.04 \\
\hline
\end{tabular}

The fit of the model has been verified by the calculation of the coefficient $\left(\mathrm{R}^{2}\right)$. In this case, the value of the coefficient is $89 \%$. This value indicates that only $11 \%$ of the variation is not explained by the model.
The test based on the distribution of Fisher ( $F$ test) in Table 4, indicates that the fitted equation is statistically significant $(\mathrm{F}=5.18<9.01)$ and that there is a good agreement between the predicted response of the model and the experimental values.

Table 4. Analysis of variance.

\begin{tabular}{|c|c|c|c|c|}
\hline & Squares of squares & Degrees of freedom & $F_{\text {calculated }}$ & $F_{\text {observed }}$ \\
\hline Regression & 0.1141 & 5 & & \\
\hline Residues & 0.0132 & 3 & 5.18 & 9.01 \\
\hline Total & 0.1271 & 8 & & \\
\hline
\end{tabular}

This model allows the plotting of the isoresponse curve (A) and the response surface curve (B) in Figure 3. These curves show the effect of $\mathrm{pH}$ and Aluminum sulphate dose on the reduction of residual Aluminum. The interaction effect between the $\mathrm{pH}$ and the Aluminum sulphate dose indicates that an appropriate adjustment of these two factors allows optimization of the residual Aluminum. The minimum value of the residual Aluminum was obtained near the central values of the $\mathrm{pH}$ and the dose of Aluminum sulphate. Optimum conditions for the maximum reduction of the residual Aluminum were observed at a $\mathrm{pH}$ of 6.5 and a dose of Aluminum sulphate of $18.5 \mathrm{mg} / \mathrm{L}$. The minimum value of residual Aluminum is $0.03 \mathrm{mg} / \mathrm{L}$. This value meets the requirement for membrane suppliers (Al <0.05 mg / L). 


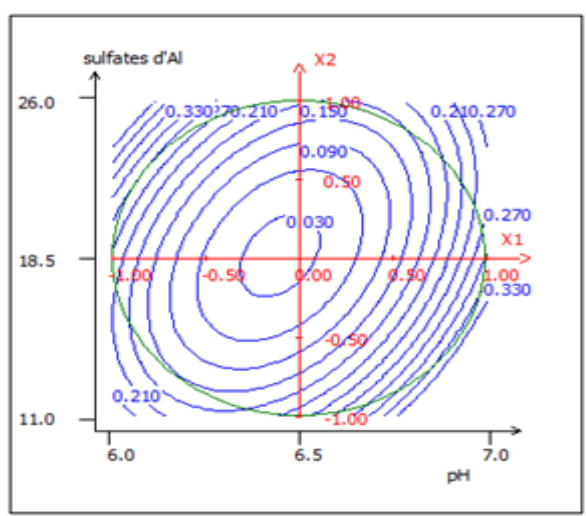

(A)

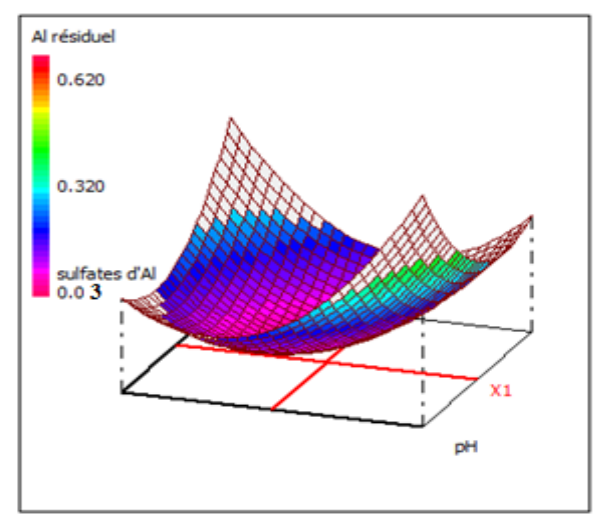

(B)

Figure 3. isoreponse curve (A) and the response surface (B) of residual Aluminum depending on the $\mathrm{pH}$ and Aluminum sulphate.

The doses of Aluminum sulphate depend on the quality of the raw water (turbidity and suspended load), it is necessary to adjust the $\mathrm{pH}$ to a value of the order of 6.5 by adding sulphuric acid to optimize the residual Aluminum content.

\section{Optimization of the sludge recirculation.}

\section{Sludge recirculation.}

Sludge recirculation is still the cheapest method to improve flocculation and reduce turbidity in a conventional treatment plant, particularly when the raw water turbidity is low and there not enough Total Suspended Solid to coagulate easily. The response surface methodology based on the Doehlert matrix was used. 15 experimental trials with various combinations of the three factors were performed. The variables used in the analysis are $\mathrm{pH}\left(\mathrm{X}_{1}\right)$. The dose of Aluminum sulphate $\left(\mathrm{X}_{2}\right)$ and the concentration of sludge $\left(\mathrm{X}_{3}\right)$. The experimental data were processed using statistical analysis. By applying a multiple regression on the analysis of the experimental data, a second order polynomial equation 3 representing the optimization of the residual Aluminum:

$Y=(-0.035) X_{1}+0.05 X_{2}+0.029 X_{3}+0.115 X_{1}^{2}+0.087 X_{2}^{2}+0.089 X_{3}^{2}+0.07 X_{1}(-0.04) X_{1} X_{3}+$ $0.196 X_{2} X_{3}$

The graphical representations of the influence of the

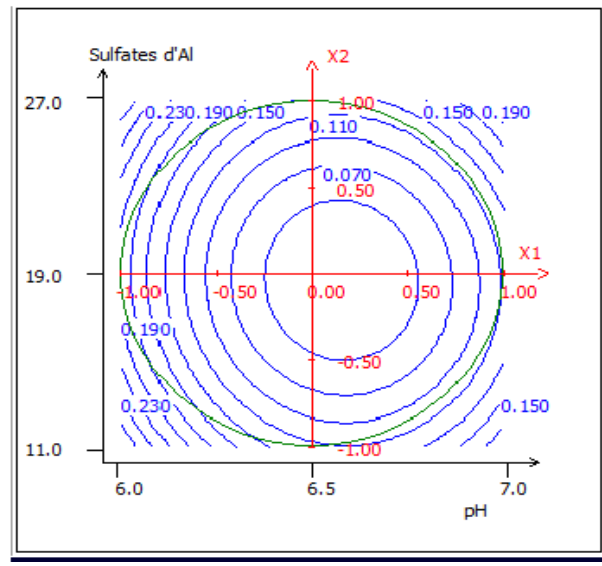

parameters on residual Aluminum, based on equation 3 are shown in Figure 4.

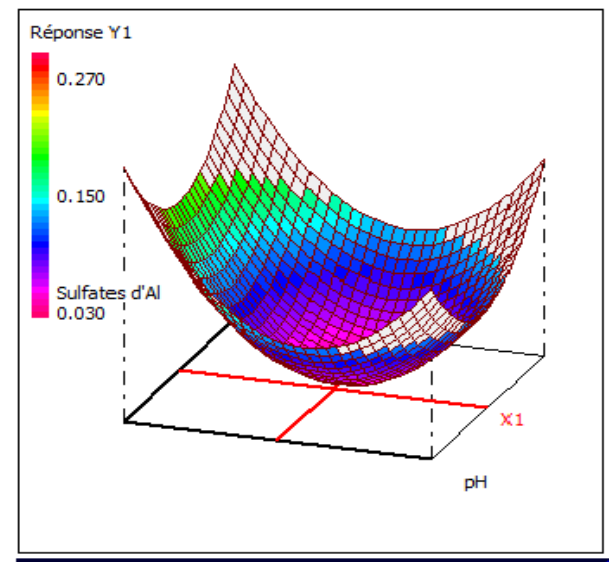

Figure 4. The isoreponse (A) curve and surface (B) response of residual Aluminum compared to $\mathrm{X}_{1}(\mathrm{pH}) . \mathrm{X}_{2}$ (Aluminum Sulphates) and recirculation of mud

The analysis of variance data shows a square value of the correlation coefficient of 0.9582 , which indicates a good fit between the experimental data and the model output. Thus, the proposed model can be used successfully to establish the optimal parameters of the coagulation process. It can be seen that the three factors have a significant influence on the effectiveness of coagulation. Thus, an increase in the concentration of the sludge leads to poor treatment, while the optimization of $\mathrm{pH}$, Aluminum sulphate and sludge concentration lead to an optimal range to obtain a residual Aluminum meets the requirements of the membranes feed water. This behaviour can be easily observed in the $3 \mathrm{D}$ plots and their corresponding contour curves, shown in Figure 4. The 
$\mathrm{pH}$ and Aluminum sulphate dose have important effects on the removal efficiency of the residual Aluminum. The optimal range can be identified at moderate doses of Aluminum sulphate $(19 \mathrm{mg} / \mathrm{L})$, for $\mathrm{pH}$ values corresponding to natural surface waters (6.5) and sludge concentration of $(0.3 \mathrm{mg} / \mathrm{L})^{17}$.

\section{Conclusion}

This study has allowed optimization of the conventional treatment plant parameters for a better operating of reverse osmosis unit downstream.

The response methodology based on the Doehlert surface matrix allowed the determination of the optimal $\mathrm{pH}$ values, the Aluminum sulphate dose and the sludge recirculation rate for better optimization of the residual Aluminum.

The doses of Aluminum sulphate depend on the quality of the raw water (turbidity and Total Suspended Solid. This study showed that it is necessary to adjust the $\mathrm{pH}$ to a value near 6.5 by adding sulphuric acid in order to optimize the residual Aluminum content.

According to the model, the minimum value of residual Aluminum is $0.03 \mathrm{mg} / \mathrm{L}$ when the parameters of $\mathrm{pH}$, the concentration of Aluminum sulphate and the concentration of the sludge are respectively 6.5 , $19 \mathrm{mg} / \mathrm{L}$ and $0.3 \mathrm{~g} / \mathrm{L}$. The validity of the model was shown by performing predicted experiments for the three variables and adjusting the values of the variables in the second order polynomial equation.

The $\mathrm{pH}$ and the dose of Aluminum sulphate exert a significant influence on the reduction of residual Aluminum while sludge recirculation has improved the turbidity of decanted water without any effect on the residual Aluminum concentration.

\section{Acknowledgements}

This work was done as part of a draft agreement for execution of doctorate between the University Mohammed V of Rabat (Faculty of sciences) and the National Office of Electricity and Drinking water in Rabat (ONEE) (Water quality control Directorate). The authors express their thanks for this support.

\section{References}

1- A. Lachheb, S. Belhamidi, N. Zouhri, Y. A. Idrissi, M. Hafsi, M. Taky, M. El Amranil and A. Elmidaoui, Performances analysis of the reverse osmosis desalination plant of brackish water used for drinking water: Tagounite, Morocco, Journal of Chemical and Pharmaceutical Research, 2016,119-129.

2- M. Farhaoui, M. Derraz, Review on Optimization of Drinking Water Treatment Process, Journal of Water Resource and Protection, 2016, 777-786.

3- T. H. Karim, B. Brahim, B.A. Mansri, Comparative Study Between New Polyacrylamide Based Copolymer Poly(AM4VP) and a Cationic Commercial Flocculant: Application in Turbidity Removal on SemiIndustrial Pilot, Journal of Polymers and the Environment, 2018, 1550-1558.

4- B. Meghzili, Z. Marsa, M.S. Medjram, Catal. Sci. Technol, 2008, 71-78

5- R. Babu, N.S. Badri Narayana, N.S. Begum, N. Anantharaman, J. Chem. Technol. Metall, 2007, 201-206.

6- A. Mukheled, Int. J. Water Res. Environ. Eng, 2012, 4, 79-92.

7- $\quad$ E. Lefebvre, Wat.Sci.Tech, 1990, 591-606.

8- P.K. Raghuwanshi, M. Mandloi, A.J. Sharma, H.S. Malviya, S. Chaudhari, Int J Environ Res Public Health. 2, 2014, 47-58.

9- N. E L Harrak, F. Elazhar, S. Belhamidi, M. Elazhar, J. Touir, A. Elmidaoui, Journal of Materials and Environmental Science, 2015, 383-390.

10- M. Hafsi, A. Khaoua, S. Ben Abdellah, M. E1 Mghari, Desalination, 2004,167, 209-216.

11- E. O. Oke, L.A. Jimoda, D.O. Araromi, Determination of biocoagulant dosage for water clarification using developed neuro-fuzzy network integrated with a user-interface-based calculator, Water Science and Technology: Water Supply, 2017,18, 1783-1792.

12- B. Lamrini, E.K. Lakhal, A Survey of Deep Learning Methods for WTP Control and Monitoring, Desalination and Water Treatment, 2018.

13- J. GOUPY, Plans d'expériences pour surfaces de réponse Ed. Dunod, 1999.

14- E.P. George, B. Norman, R. Draper, Empirical model-building and response surface, Ed. John Wiley \&Sons, 1987.

15- D.H. Doehlert, Uniform shell designs, 1970, 231-9.

16- C.T. Driscollm, W.D. Schecher, A.M.A. Arch. Ind. Health, 1988, 59-122.

17- M. Farhaoui, M. Derraz, J. Chem. Pharm. Res, 2016, 749-775. 